\title{
Transformational Leadership Spur Organizational Commitment among Optimistic Followers: The Role of Psychological Capital
}

\author{
Chunhui Huo ${ }^{1}$, Muhammad Waheed Akhtar', Muhammad Arslan Safdar ${ }^{3}$, Muhammad \\ Kashif Aslam ${ }^{4}$, Khurram Abbas ${ }^{5}$, Muhammad Hasan Rafiq ${ }^{6}$, Kamran Iqbal $^{7}$
}

\author{
1,3, Asia-Australia Business College, Liaoning University, Shenyang, P.R. China \\ $2^{*}, 4,5,6$, Department of Management Sciences, COMSATS University Islamabad, Sahiwal Campus, Pakistan \\ ${ }^{7}$ Department of Management Sciences, University of Lahore, Sargodha Campus, Pakistan
}

Keywords:

Transformational leadership, Organizational commitment, Psychological capital, Nurses, Pakistan

\section{Received}

30 July 2020

Received in revised form

09 August 2020

Accepted

14 August 2020

\begin{abstract}
The present study aims to investigate the effect of transformational leadership on psychological capital and organizational commitment. In addition, this study investigates the effect of psychological capital on organizational commitment. Furthermore, this study also investigates the mediating effect of psychological capital on the relationship between transformational leadership and organizational commitment under the lens of social exchange theory. Three hundred-fifty survey questionnaires were distributed among employees of the health sector to test the hypotheses of this study. We validated the proposed framework using the mediation technique. The results indicated that transformational leadership is significantly related to organizational commitment and psychological capital. Further, results also revealed that psychological capital is significantly related to organizational commitment. Moreover, the results also showed that psychological capital mediates the relationship between transformational leadership and organizational commitment. This study will be significant for the managers and employees in the health sector who need to understand that transformational leaders promote psychological capital, which ultimately enhances organizational commitment. Healthcare management should arrange training programs on transformational leadership styles for managers because transformational leaders gain their subordinates' trust due to their devotion and contributions. The limitations of this study and future directions are also provided in the discussion section.
\end{abstract}


Service sector makes hefty contributions in the well-being and economy of Pakistan; however, health sector is a major contributor (Rasool, Arfeen, Mothi, \& Aslam, 2015; Syed et al., 2020). The effectiveness of the health sector positively influences the general health of individual Pakistanis. This important duty requires the regulation of health attributes in hospitals (Tabiby, Tourani, \& EbadiFard Azar, 2001). Role of human resources is of pivotal importance in health care sector because they are directly connected with patients and they provide services with full commitment, which is why hospital management empowers their nursing staff to achieve organizational goals (Regan, Laschinger, \& Wong, 2016). Nurses' commitment and dedication are indispensable given the fact that they lead to patients' satisfaction and the achievement of hospital goals (Sereshti et al., 2016). According to Rasool et al. (2015), research in past decade has greatly focused on leadership. Leaders are significant contributors in shaping employees' attitudes and behaviors (Puni, Mohammed, \& Asamoah, 2018). Prior research has mentioned that leaders leave their impression on employees' attitudes and behaviors in the health sector (Turner, 2019), including studies on transformational leaders (Alghamdi, Topp, \& AlYami, 2018; Fenwick, Brimhall, Hurlburt, \& Aarons, 2018), transactional leaders (Rasool et al., 2015), leader-member exchange (Mostafa \& ElMotalib, 2018), ethical leaders (Kamal, Samdani, Zara, \& Kamal, 2018), servant leaders (Kamal et al., 2018) and authentic leaders (Bakari, Hunjra, Jaros, \& Khoso, 2018). Bass and Bass (2009) stated that leadership styles vary from situation to situation and individual to individual.

With knowledge-based view taking over resource-based view, employee importance has been on the increase specifically in transforming organizations (Chuang, 2004). However, transformational leadership (TL) style best fits the health sector because TL focuses on employees' change and transformation (Northouse, 2013), and TL also addresses organizational issues related to trust, commitment and job satisfaction (Yang, 2016), which is why, this style is mostly suited to today's dynamic organizations to achieve organizational performance and goals (Judge \& Piccolo, 2004). Northouse (2013) defined TL as "the process whereby a person engages with others and creates a connection that raises the level of motivation and morality in both the leader and the follower" (p. 186). Bass and Riggio (2006) argued that followers' development is in the DNA of transformational leaders. According to Northouse (2013), that transformational leader's motives entail encouraging and enabling their followers to put extra efforts and achieve outstanding results. Smith (2011) deliberates that transformational leaders focus on to empower their followers, boost their self-esteem and spur teamwork. A transformational leader has six traits, i.e., "identifying and articulating a vision, providing an appropriate model, fostering the acceptance of group goals, high-performance expectations, providing individualized support and intellectual stimulation"(Podsakoff, MacKenzie, Moorman, \& Fetter, 1990, p. 112). These traits are the building blocks of transformational leaders making it the most applied and suitable style in health sector. 


\section{Literature Review}

\section{TL and Organizational Commitment}

Meyer and Allen (1991) define Organizational commitment (OC) as "a psychological state that binds the individual to the organization" (p. 14). Avolio, Gardner, Walumbwa, Luthans, and May (2004) found positive affiliation among two aspects for nurses in Singapore: TL and OC. Among all leadership styles, TL has been judged as the best for improving employees' productivity, and their commitment is promoted by TL (Limsili, Ogunlana, Mathis, \& \& Jackson, 2008). Ismail and Yusuf (2009) contest that TL has a positive and significant relationship with followers' commitment. Previous studies have also discovered the significant and positive relationship of TL with healthcare workers' commitment level (Ennis, Gong, \& Okpozo, 2018; Rasheed, 2018).

According to Rhéaume, Clément, and Lebel (2011), health sector employees intend to quit in the first few years at their jobs. According to previous studies, there exists the significant positive relationship between transformational leaders and health care employee outcomes (Cho et al., 2019; Manesh, Singh, \& Hussain, 2018). A TL creates a friendly and supportive environment at the workplace with a focus on individual employees' needs and preferences and expresses concern for subordinates and then, reciprocates it with their increased commitment towards the organizations. Therefore, we propose the following hypothesis:

$\mathrm{H}_{1}$ : TL is positively related to OC.

\section{TL and Psychological Capital}

Psychological capital is defined as "the individual's positive evaluation of a situation and his or her likelihood of success based upon motivational efforts and willpower" (Luthans, Youssef, \& Avolio, 2007, p. 3 ). According to Luthans et al. (2007) psychological capital contains four dimensions, i.e. hope, optimism, self-efficacy, and resilience. A TL can influence employees' core beliefs, ethics, and goals (Bass, 1985).

Previous research concluded that a TL is positively related with employees' psychological capital (Schuckert, Kim, Paek, \& Lee, 2018; Yuan, Nguyen, \& Vu, 2018). TL encourages their followers by providing constructive feedback to them by setting an expectation of the model behavior for their role, which leads to a constructive environment at the workplace for their followers, who are resilient, hopeful, efficacious and optimistic. Therefore, based on the above literature, we propose the following hypothesis:

$\mathbf{H}_{2}$ : TL is positively related to psychological capital.

\section{Psychological Capital and OC}

Luthans et al. (2007) reported that the dimensions of psychological capital (resilience, self-efficacy, hope, and optimism) are positively related to attitudinal/behavioral outcomes of employees at the workplace. Prior studies have established that psychological capital works best for those who believe that more efficient and successful work is produced due to higher optimism and faith in their capabilities, which brings higher level satisfaction and increased OC (Avey, Reichard, Luthans, \& Mhatre, 2011). According to Luthans and Jensen (2005), psychological capital 
effectively enhances OC among healthcare sector workers. Ghaffaripour (2015) found a significantly positive relationship of psychological capital with affective OC. Thus, we propose the following hypothesis:

H3: Psychological capital is positively related to OC.

\section{Mediating Role of Psychological Capital}

According to Liu, Hu, Wang, Sui, and Ma (2013), enhanced psychological capital level of employees attracts increased level of supervisor support, which also increases their performance level. According to Luthans, Avey, Avolio, and Peterson (2010), psychological capital indirectly affects the link of supportive organizational climate and job performance. Maintaining satisfaction among workers or being friendly with other members is a socialization tool implied by the firms to guide newcomers and increase their level of psychological capital, resulting in highly motivated and engaged workers (Nigah, Davis, \& Hurrell, 2012). Liu, Wang, Ji, Jiang, and Chang (2012) stated that psychological capital is negatively related to depressive symptoms among female nurses.

Liu et al. (2012) investigated the indirect influence that the psychological capital bears on workfamily conflict and burnout relationship. According to Epitropaki (2013), there exists an inverse relationship between employment uncertainty and psychological capital. Prior studies have examined the gender role orientation of a worker in relation to his or her psychological capital and perception of career success (Ngo, Foley, Ji, \& Loi, 2014). Recent studies have elaborated how psychological capital plays its indirect role in transformation leadership relationship with employee outcomes (Schuckert et al., 2018; Yuan et al., 2018). Based on the abovementioned literature and the relationships between TL and OC, TL and psychological capital, and psychological capital and OC, as displayed in Figure 1, we propose the following hypothesis:

H4: Psychological capital mediates the relationship between TL and OC.

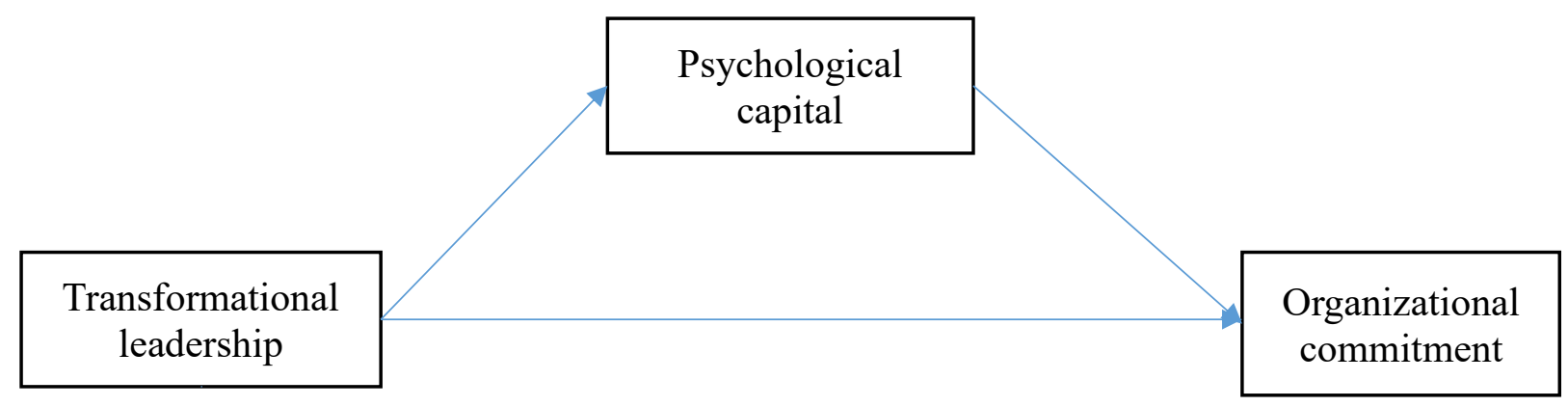

Figure 1. Theoretical framework of the study.

\section{Research Objectives}

Recent studies have investigated the effect of TL on OC (Cho, Shin, Billing, \& Bhagat, 2019; Jain \& Duggal, 2018). Recently, a handful of research has studied psychological capital and OC relationship (Wu \& Chen, 2018; Zhou et al., 2018). However, there research has glossed 
over TL in the healthcare setting of Pakistan (Asrar-Ul-Haq et al., 2020; Khan \& Nawaz, 2016). There exists scant knowledge of the psychological mechanisms through which this relationship occurs. Particularly, the mediational impact of psychological capital on the link between TL and OC still remains uninvestigated. In the present study, we focused on the healthcare sector since, in recent years, economic crises have contributed significant changes in the healthcare sector. Top management has fewer resources and voluminous effecting workers' OC level. With this in mind, only the leader/supervisor can maintain their followers' attitudes. Healthcare employees closely interact with patients, assess patient's needs and meet them accurately (Nielsen, Yarker, Randall, \& Munir, 2009). Therefore, top management should identify and train transformational leaders in order to motivate and pump up their followers/subordinates to take on responsibilities (Dunham-Taylor, 2000). Thus, present study aims to investigate the impact of TL on OC via psychological capital. Present study will help to expand the literature by investigating the aforementioned relationship. This study addresses the following research questions:

1. What is the relationship between TL and OC?

2. Does TL affect employee psychological capital?

3. Does the psychological capital mediate the relationship between TL and OC?

\section{Method}

The current study discusses how transformational influences psychological capital and OC. Further, the study investigates the direct relationship between psychological capital and OC and mediational role of psychological capital on the direct effect of TL on OC among healthcare sector employees, i.e., nurses, as Figure 1 elaborates. The present research study is cross-sectional and used a deductive approach. Through survey questionnaires, data were collected from nurses using convenience sampling technique. The survey questionnaires were distributed among nurses in public and private hospitals in February and March 2018.

First, respondents were briefed about the survey purpose and respondents were assured of the anonymity of the survey and about research purpose data utilization only. Survey based research conducted with different sample size. Kelloway (1998) stated minimum 200 respondents as sample size for survey based research. Boomsma (1983) proposed 350 to 400 respondents as sample size for mediational nature complex models. Thus, present study is complex model in nature. Initially, we distributed 430 survey questionnaires among nurses, and we received 320 questionnaires back. Among the surveys, 17 had incomplete responses and high numbers of missing responses, so we discarded those surveys. Finally, we had 303 properly completed responses with a valid response rate of $70 \%$. In this study, we collected demographic feedback of the respondents as well, i.e., gender, age, education, marital status, and working experience. Most of the respondents were female (270), almost 90 percent of the total sample. Mostly the respondent were 23-30 years old (129), 43 percent of the total sample. 56 percent of the respondents had an intermediate level education (171) and 66 percent of the sample were single (199). One hundred fifty-eight respondents had 2-5 years of work experience, 52 percent of the sample. 


\section{Variable Measurement}

Transformational Leadership: To measure TL, we used the seven item scale developed by Carless, Wearing, and Mann (2000). The sample questions included "treats staff as individuals, supports and encourage their development" and had a reliability of 0.83 .

Psychological Capital: Psychological capital was measured according to a twenty-four item scale developed by Luthans et al. (2007). The sample questions included "I feel confident analyzing a long-term problem to find a solution" and had a reliability of 0.91 .

Organizational commitment $(O C)$ : OC was measured with the scale of Meyer, Allen, and Smith (1993) with eighteen items.. The sample questions include "Willing to put forth great effort to help an organization succeed" and had a reliability of 0.79 . All the responses were anchored by using a five-point Likert scale ranging from strongly disagree to strongly agree.

\section{Results}

Table 1 illustrates the descriptive statistics, Cronbach's alphas and correlation analyses of all the study variables (TL, OC, and psychological capital). Above 0.70 Cronbach's alpha scores as reported confirm the reliability of the measurement scales as they were all above 0.70 , the cut-off value recommended by Nunnally (1978).

Table 1

Correlation Analysis Results

\begin{tabular}{|c|c|c|c|c|c|c|}
\hline Sr.no & & $M$ & $S D$ & 1 & 2 & 3 \\
\hline 1 & Transformational Leadership & 3.58 & 0.76 & $(.77)$ & & \\
\hline 2 & Psychological Capital & 3.81 & 0.64 & $.59^{* *}$ & $(.92)$ & \\
\hline 3 & Organizational Commitment & 3.31 & 0.57 & $.29 * *$ & $.37 * *$ & (.73) \\
\hline
\end{tabular}

Table 1 shows that TL enjoys a significantly positive correlation with OC $(r=.29, p<.01)$. The results also show that a significant and positive correlation exists between TL and psychological capital $(\mathrm{r}=.59, p<.01)$ as well as between psychological capital and OC $(\mathrm{r}=.370, p<.01)$.

To assess hypothesis related to psychological capital mediation effect and the indirect effect of TL on OC via psychological capital, we used four relationships recommended by Baron and Kenny (1986). First, TL (independent variable) is significantly related to OC (dependent variable). Second, TL (independent variable) significantly influences psychological capital (mediating variable). Third, psychological capital (mediating variable) depicts significant positive impact on OC (dependent variable). Finally, psychological commitment when introduced reduces the direct impact of TL on OC. Preacher and Hayes (2004) technique was used to conduct the principal effect analysis and mediational analysis.

The analysis results of hypothesized model in Table 2 indicates that TL significantly influences $\mathrm{OC}$ in positive dimension $(\beta=.18, p<.01)$. The $\mathrm{R}$ squared $\left(\mathrm{R}^{2}\right)$ value of .08 indicates 
that $8 \%$ of the variance in OC is explained by TL. Hence, the results support our first hypothesis. The R2 value of .48 indicates that $47.8 \%$ of the variance in psychological capital is explained by TL. This results also supports the hypothesis and has a positive $(\beta=.59$, $p<.01)$ and significant beta coefficient. Therefore, hypothesis 2 is also supported.

Table 2

Main Effect Regressions

\begin{tabular}{|c|c|c|c|c|c|c|}
\hline Sr. No & Variable & $\mathrm{R}^{2}$ & $\beta$ & $S E$ & $t$ & $p$ \\
\hline 1 & $\begin{array}{l}\text { Transformational Leader } \rightarrow \text { Organizational } \\
\text { Commitment }\end{array}$ & .08 & .18 & .03 & 5.24 & .000 \\
\hline 2 & $\begin{array}{l}\text { Transformational Leader } \rightarrow \text { Psychological } \\
\text { Capital }\end{array}$ & .48 & .59 & .04 & 16.61 & .000 \\
\hline 3 & $\begin{array}{l}\text { Psychological Capital } \\
\text { Commitment }\end{array}$ & .14 & .24 & .06 & 4.38 & .000 \\
\hline
\end{tabular}

Note: $\mathrm{n}=303$. Bootstrap sample size $=10000 . \mathrm{LL}=$ Lower limit, $\mathrm{CI}=$ Confidence Interval, and UL $=$ Upper Limit. Path- $1=\mathrm{IV} \rightarrow \mathrm{DV}$, Path$2=\mathrm{IV} \rightarrow \mathrm{MV}$, Path $-3=\mathrm{MV} \rightarrow \mathrm{DV}$.

The $\mathrm{R}^{2}$ value of .14 indicates that $13.7 \%$ of the variance in $\mathrm{OC}$ is explained by psychological capital. This result also reveals that psychological capital has a significant and positive effect on OC $(\beta=.24, p<.01)$. Therefore, hypothesis 3 is also supported.

Table 3 reveals that psychological capital mediates the relationship between TL and OC because the confidence intervals of the indirect effect (.14) do not reach zero between the upper limit and lower limit (.08 and .23, respectively), which was also confirmed through the Sobel test (effect $=.14, \mathrm{z}=4.23, p=.000$ ). Therefore, hypothesis 4 is also supported.

Table 3

Indirect Effect of Psychological Capital

\begin{tabular}{|c|c|c|c|c|c|}
\hline & Indirect Effect via the Sobel test & & & & \\
\hline \multirow{4}{*}{ Sobel } & & Effect & $S E$ & $Z$ & $p$ \\
\hline & & .14 & .03 & 4.23 & .000 \\
\hline & \multicolumn{5}{|c|}{ Indirect Effects via Bootstrapping results } \\
\hline & & $M$ & $S E$ & LL95\% CI & UL $95 \%$ CI \\
\hline Psychological Capital & & .14 & .03 & .08 & .23 \\
\hline
\end{tabular}

Note: $\mathrm{n}=303$. Bootstrap sample size $=10000 . \mathrm{LL}=$ Lower limit, $\mathrm{CI}=$ Confidence Interval, and UL= Upper Limit.

\section{Discussion}

The goal of the study was to investigate the TL-OC relationship and to extend the understanding of psychological processes such as psychological capital as a mediational factor in defining the relationship. All hypotheses were supported. The results derived from the study support and advance prior research on TL and its impact on OC (Ennis et al., 2018; Rasheed, 2018). As TL boost followers' confidence by explaining and helping them about how to reach the goals. Thus, when a leader displays such type of behaviours, then followers are more likely to achieve their goals and thus this will enhance their OC level. Second, the findings established 
TL as positive and significant influencer on psychological capital, thus extending extant literature on these constructs (Schuckert et al., 2018; Yuan et al., 2018). As TL inspires and motivates their followers. TL focusses on followers learning by sharing their experiences and delegating authority. Thus, followers under TL are more inclined towards psychological capital. the effectiveness of psychological capital as a potential influencer on establishes the reliability of prior research on the topic (Avey et al., 2011). Third, as the psychological capital is the combination of self-efficacy, hope, optimism and resilience. All these dimensions boost OC. Individuals with high self-efficacy level are confidant and they insert high level efforts for task accomplishment. Optimist individual have the attribution for current and future success; thus, they are highly committed. Under the hope dimension, followers preserve and redirect their effort for goal accomplishment. Past studies reported that psychological capital boost OC. Fourth, the findings also concert with previous results identifying psychological capital as a critical mediator linking TL and OC. Past studies also stated the mediating role of psychological capital (Carmona-Halty, Schaufeli, \& Salanova, 2019; Liao, Hu, Chung, \& Chen, 2017; Tian et al., 2020).

The results of this study suggest that higher levels of psychological capital facilitate the nurses in attaining their individual as well as organizational goals. Moreover, this increased level of psychological capital makes them distinctive in the eyes of their manager and supervisors and their management identifies them as resources capable of seamlessly hitting the targets set by the organization. This analysis explores the significant positive relation with psychological capital, since due to the expanding complexities of the business world, market risk, and employees' behavior, it is good for entrepreneurs to spend capital to advance the psychological capital of their leaders. In this way, the impact trickles down throughout the organizations. It is easy for lower organizational members to imitate their leaders once the leaders are masters and exhibit positive psychological capacities.

\section{Conclusion}

The obtained findings in this study will guide human resource professionals and administrators in the healthcare field towards developing a better understanding of the issues faced by employees and allow them to develop programs in accordance with these issues, which would ultimately lead to increased levels of employees' commitment. Human resources add competitive advantage to the organizations and these assets are indispensable for any organizations. Improving employee commitment and enhancing their performance are the most desirable factors for any organization. The study established that TL affects OC and psychological capital, both directly and indirectly. Therefore, organizations should strive to implement a TL style. These results of our study are conclusive to support to adopt TL style so that the upper management in health care sector work for improved psychological capital of their nursing staff, which in turn, will increase their OC. 


\section{Study Implications}

The theoretical contribution of the present study is that it investigated the mediating role of psychological capital in the relationship between TL and OC. Recently, Meyer (2016) suggested that further studies are needed to identify the antecedents of OC; however, before now, no study has investigated the mediating role of psychological capital in the relationship between TL and OC among employees in the health sector.

The qualities of TL are shown to be effective at encouraging staff members and for upperlevel decision making (Dunham, 1990). TL is affiliated with satisfactory performance and greater productivity among workers (Bass, 1985). Therefore, it would be beneficial for nursing executives to hire employees with transformational characteristics and to establish these characteristics in their staff members. Studies concentrated on leadership training have suggested that these dimensions of TL can be learned from leadership programs (Bass \& Stogdill, 1990) with favorable implications for staff development programs. Hence, by following the model, nursing executives can obtain fruitful results. TL are perceived to be opinion leaders and influential people in the given environment because they provide direction to their followers, which is why TL play an effective role among health sector employees (Ahmad, Adi, Noor, Rahman, \& Yushuang, 2013).

TL possesses more dignity and trust in the workplace due to his or her devotion, maintains a positive outlook, and also rewards others based on their contributions. Therefore, healthcare sector management should provide training and opportunities for their managers or leaders to learn these types of practices, activities, and qualities. Healthcare sector managers promote and enhance the psychological capital among their followers so that their OC is increased. The present study suggests that managers or supervisors should take remedial measures to reduce the politics in their organization and improve the OC among nurses by developing TL qualities.

\section{Limitations and Future Directions}

The present study has certain limitations. The first limitation is that present study used a crosssectional design due to its causal relationship. We collected data from health sector employees through a survey questionnaire at a single time point; therefore, there is a likelihood of respondent biases, which is why future studies should focus on time-lagged and longitudinal approaches to reduce respondent bias. The second limitation is that we used single-source data (self-reported), and the same individual provided data about all the three constructs i.e., TL, psychological capital and OC. Future studies, in order to minimize the common method bias, should use a combination of different sources for data collection i.e supervisors, peers, and subordinates. Third, the present study sample characteristics also limit the scope of the study. With data collection made from Pakistani healthcare sector employees, there might arise generalizability issues. Therefore, future studies should examine the present model in different sectors and cultures. The fourth limitation is that this study used only psychological capital as the mediator to investigate the indirect influence of TL on OC. Future research needs to consider other variables as potential mediators, e.g., emotional intelligence, trust, personorganization fit, and shared vision. The fifth limitation is that this study investigated the impact of positive style of leadership such as TL while future studies should investigate the negative leadership shades as supervisor ostracism (Akhtar, Syed, Javed, \& Husnain, 2020) and exploitative leadership (Syed, Akhtar, Kashif, \& Husnain, 2019). 


\section{References}

Ahmad, A. R., Adi, M. N. M., Noor, H. M., Rahman, A. G. A., \& Yushuang, T. (2013). The influence of leadership style on job satisfaction among nurses. Asian Social Science, 9(9), 172.

Akhtar, M. W., Syed, F., Javed, M., \& Husnain, M. (2020). Grey shade of work environment triad-effect of supervisor ostracism and perceived organizational obstruction on employees' behaviour: a moderated-mediation model. Leadership and Organization Development Journal, 41(5), 669-686.

Alghamdi, M. G., Topp, R., \& AlYami, M. S. (2018). The effect of gender on transformational leadership and job satisfaction among Saudi nurses. Journal of Advanced Nursing, 74(1), 119-127.

Asrar-Ul-Haq, M., Amin, S., Ali, H. Y., Akhtar, M. W., Ali, M., Noor, S., . . Khalid, A. (2020). Congruence of perceptions between bank managers and subordinates about leadership style and performance in Pakistan. Cogent Business and Management, 7(1), 1796270.

Avey, J. B., Reichard, R. J., Luthans, F., \& Mhatre, K. H. (2011). Meta-analysis of the impact of positive psychological capital on employee attitudes, behaviors, and performance. Human resource Development Quarterly, 22(2), 127-152.

Avolio, B. J., Gardner, W. L., Walumbwa, F. O., Luthans, F., \& May, D. R. (2004). Unlocking the mask: A look at the process by which authentic leaders impact follower attitudes and behaviors. The Leadership Quarterly, 15(6), 801-823.

Bakari, H., Hunjra, A. I., Jaros, S., \& Khoso, I. (2018). Moderating role of cynicism about organizational change between authentic leadership and commitment to change in Pakistani public sector hospitals. Leadership in Health Services, 32(3), 387-404.

Baron, R. M., \& Kenny, D. A. (1986). The moderator-mediator variable distinction in social psychological research: Conceptual, strategic, and statistical considerations. Journal of Personality and Social Psychology, 51(6), 1173-1182.

Bass, B. M. (1985). Leadership: Good, better, best. Organizational Dynamics, 13(3), 26-40.

Bass, B. M., \& Bass, R. (2009). The Bass handbook of leadership: Theory, research, and managerial applications. Simon and Schuster.

Bass, B. M., \& Riggio, R. E. (2006). Transformational leadership. Psychology Press.

Bass, B. M., \& Stogdill, R. M. (1990). Bass \& Stogdill's handbook of leadership: Theory, research, and managerial applications. Simon and Schuster.

Boomsma, A. (1983). On the robustness of LISREL (maximum likelihood estimation) against small sample size and nonnormality. Groningen: s.n.

Carless, S. A., Wearing, A. J., \& Mann, L. (2000). A short measure of transformational leadership. Journal of Business and Psychology, 14(3), 389-405.

Carmona-Halty, M., Schaufeli, W. B., \& Salanova, M. (2019). Good relationships, good performance: the mediating role of psychological capital-a three-wave study among students. Frontiers in Psychology, 10, 306.

Cho, Y., Shin, M., Billing, T. K., \& Bhagat, R. S. (2019). Transformational leadership, transactional leadership, and affective organizational commitment: a closer look at their relationships in two distinct national contexts. Asian Business and Management, 18(3), 187-210..

Chuang, S. H. (2004). A resource-based perspective on knowledge management capability and competitive advantage: an empirical investigation. Expert Systems with Applications, 27(3), 459-465.

Dunham-Taylor, J. (2000). Nurse executive transformational leadership found in participative organizations. Journal of Nursing Administration, 30(5), 241-250.

Dunham, W. (1990). Journey through genius: The great theorems of mathematics. Wiley.

Ennis, M. C., Gong, T., \& Okpozo, A. Z. (2018). Examining the mediating roles of affective and normative commitment in the relationship between transformational leadership practices and turnover intention of government employees. International Journal of Public Administration, 41(3), 203-215.

Epitropaki, O. (2013). A multi-level investigation of psychological contract breach and organizational identification through the lens of perceived organizational membership: Testing a moderated-mediated model. Journal of Organizational Behavior, 34(1), 65-86. 
Fenwick, K. M., Brimhall, K. C., Hurlburt, M., \& Aarons, G. (2018). Who wants feedback? Effects of transformational leadership and leader-member exchange on mental health practitioners' attitudes toward feedback. Psychiatric Services, 70(1), 11-18.

Ghaffaripour, S. (2015). Prediction of affective organizational commitment based on employee characteristics and psychological factors among oil personnel. International Journal of Management and Business Research, 5(4), 337-350.

Ismail, A., \& Yusuf, M. H. (2009). The relationship between transformational leadership, empowerment and organizational commitment: A mediating model testing. Timisoara Journal of Economics, 2(2 (6)), 101-110.

Jain, P., \& Duggal, T. (2018). Transformational leadership, organizational commitment, emotional intelligence and job autonomy: Empirical analysis on the moderating and mediating variables. Management Research Review, 41(9), 10331046.

Judge, T. A., \& Piccolo, R. F. (2004). Transformational and transactional leadership: a meta-analytic test of their relative validity. Journal of Applied Psychology, 89(5), 755-768.

Kamal, N., Samdani, H., Zara, B., \& Kamal, K. (2018). Influence of ethical leadership on health care climate of innovation in Pakistan. Pakistan Journal of Public Health, 8(4), 219-224.

Kelloway, E. K. (1998). Using LISREL for structural equation modeling: A researcher's guide: Sage.

Khan, \& Nawaz, A. (2016). The leadership styles and the employees performance: A review. Gomal University Journal of Research (Sciences), 32(2), 144-150.

Liao, S. S., Hu, D. C., Chung, Y. C., \& Chen, L. W. (2017). LMX and employee satisfaction: mediating effect of psychological capital. Leadership \& Organization Development Journal, 38(3), 433-449.

Limsili, Ogunlana, Mathis, R. L., \& \& Jackson, J. H. (2008). Human Resource management (Vol. 12th ed). South-Western: Thomson.

Liu, W., Wang, J., J, R., Jiang, Y. G., \& Chang, S. F. (2012). Supervised hashing with kernels. Supervised hashing with kernels. In 2012 IEEE Conference on Computer Vision and Pattern Recognition (pp. 2074-2081). IEEE.

Liu, L., Hu, S., Wang, L., Sui, G., \& Ma, L. (2013). Positive resources for combating depressive symptoms among Chinese male correctional officers: perceived organizational support and psychological capital. BMC Psychiatry, 13(1), 89.

Luthans, F., Avey, J. B., Avolio, B. J., \& Peterson, S. J. (2010). The development and resulting performance impact of positive psychological capital. Human Resource Development Quarterly, 21(1), 41-67.

Luthans, F., \& Jensen, S. M. (2005). The linkage between psychological capital and commitment to organizational mission: A study of nurses. Journal of Nursing Administration, 35(6), 304-310.

Luthans, F., Youssef, C. M., \& Avolio, B. J. (2007). Psychological capital: Developing the human competitive edge. Oxford University Press.

Manesh, M. H., Singh, J. S. K., \& Hussain, I. A. B. (2018). Transformational leadership and contextual performance: A quantitative study among nursing staff in Kuala Lumpur. International Journal of Management and Sustainability, 7(2), $101-112$.

Meyer, J. P. (2016). Handbook of employee commitment: Edward Elgar Publishing.

Meyer, J. P., \& Allen, N. J. (1991). A three-component conceptualization of organizational commitment. Human Resource Management Review, 1(1), 61-89.

Meyer, J. P., Allen, N. J., \& Smith, C. A. (1993). Commitment to organizations and occupations: Extension and test of a three-component conceptualization. Journal of Applied Psychology, 78(4), 538-551.

Mostafa, A. M. S., \& El-Motalib, E. A. A. (2018). Servant leadership, leader-member exchange and proactive behavior in the public health sector. Public Personnel Management, 48(3), 309-324.

Ngo, H. Y., Foley, S., Ji, M. S., \& Loi, R. (2014). Linking gender role orientation to subjective career success: The mediating role of psychological capital. Journal of Career Assessment, 22(2), 290-303.

Nielsen, K., Yarker, J., Randall, R., \& Munir, F. (2009). The mediating effects of team and self-efficacy on the relationship between transformational leadership, and job satisfaction and psychological well-being in healthcare professionals: A cross-sectional questionnaire survey. International Journal of Nursing Studies, 46(9), 1236-1244.

Nigah, N., Davis, A. J., \& Hurrell, S. A. (2012). The impact of buddying on psychological capital and work engagement: An empirical study of socialization in the professional services sector. Thunderbird International Business Review, 54(6), 891-905.

Northouse, P. G. (2013). Leadership: Theory and practice (Vol. 6th ed). London: Sage publications.

Nunnally, J. (1978). Nunnally on reliability. Retrieved on June, 10, 2008. 
Podsakoff, P. M., MacKenzie, S. B., Moorman, R. H., \& Fetter, R. (1990). Transformational leader behaviors and their effects on followers' trust in leader, satisfaction, and organizational citizenship behaviors. The leadership Quarterly, 1(2), $107-142$.

Preacher, K. J., \& Hayes, A. F. (2004). SPSS and SAS procedures for estimating indirect effects in simple mediation models. Behavior Research Methods, Instruments, and Computers, 36(4), 717-731.

Puni, A., Mohammed, I., \& Asamoah, E. (2018). Transformational leadership and job satisfaction: the moderating effect of contingent reward. Leadership and Organization Development Journal, 39(4), 522-537.

Rasheed, M. H. (2018). The factors influencing job commitment of teaching staff in University of Sargodha: Mediating role of transformational leadership. International Journal of Social Sciences, Humanities and Education, 2(1), 1-17.

Rasool, H. F., Arfeen, I. U., Mothi, W., \& Aslam, U. (2015). Leadership styles and its impact on employee's performance in health sector of Pakistan. City University Research Journal, 5(1), 97-109.

Regan, S., Laschinger, H. K., \& Wong, C. A. (2016). The influence of empowerment, authentic leadership, and professional practice environments on nurses' perceived interprofessional collaboration. Journal of Nursing Management, 24(1), E54E61.

Rhéaume, A., Clément, L., \& Lebel, N. (2011). Understanding intention to leave amongst new graduate Canadian nurses: a repeated cross sectional survey. International Journal of Nursing Studies, 48(4), 490-500.

Schuckert, M., Kim, T. T., Paek, S., \& Lee, G. (2018). Motivate to innovate: How authentic and transformational leaders influence employees' psychological capital and service innovation behavior. International Journal of Contemporary Hospitality Management, 30(2), 776-796.

Sereshti, M., Nahidi, F., Simbar, M., Ahmadi, F., Bakhtiari, M., \& Zayeri, F. (2016). Mothers' perception of quality of services from health centers after perinatal loss. Electronic Physician, 8(2), 2006-2017.

Smith, M. A. (2011). Are you a transformational leader? Nursing Management, 42(9), 44-50.

Syed, F., Akhtar, M. W., Kashif, M., Asrar-ul-Haq, M., Husnain, M., \& Aslam, M. K. (2020). When leader is morally corrupt: interplay of despotic leadership and self-concordance on moral emotions and bullying behavior. Journal of Management Development. https://doi.org/10.1108/JMD-05-2019-0183

Syed, F., Akhtar, M. W., Kashif, M., \& Husnain, M. (2019, July). Interplay of Exploitative Leadership \& Fear of Negative Evaluation on Knowledge Hiding \& Outcomes. In Academy of Management Proceedings (Vol. 2019, No. 1, p. 17050). Briarcliff Manor, NY 10510: Academy of Management.

Tabiby, S. J., Tourani, S., \& EbadiFard Azar, F. (2001). Total quality management in health care, Tehran. Electronic Publishing and Informing WHO, 163-178.

Tian, F., Shu, Q., Cui, Q., Wang, L., Liu, C., \& Wu, H. (2020). The mediating role of psychological capital in the relationship between occupational stress and fatigue: A cross-sectional study among 1,104 Chinese physicians. Frontiers in Public Health, 8,12

Turner, P. (2019). Assessing health professionals for succession and leadership roles leadership in healthcare (pp. 263293). Springer.

Wu, C. M., \& Chen, T. J. (2018). Collective psychological capital: Linking shared leadership, organizational commitment, and creativity. International Journal of Hospitality Management, 74, 75-84.

Yang, Y. F. (2016). Examining competing models of transformational leadership, leadership trust, change commitment, and job satisfaction. Psychological Reports, 119(1), 154-173.

Yuan, L., Nguyen, T. T. N., \& Vu, M. C. (2018). Transformational leadership and its impact on performance: The role of psychological capital and collectivism. Proceedings of the 2018 2nd International Conference on Management Engineering, Software Engineering and Service Sciences, 18-27. https://doi.org/10.1145/3180374.3181325

Zhou, J., Yang, Y., Qiu, X., Yang, X., Pan, H., Ban, B., . . Wang, W. (2018). Serial multiple mediation of organizational commitment and job burnout in the relationship between psychological capital and anxiety in Chinese female nurses: A cross-sectional questionnaire survey. International Journal of Nursing Studies, 83, 75-82. 